\title{
Expression and activation of human endogenous retroviruses of the $W$ family in blood cells and astrocytes: implications for the pathogenesis of multiple sclerosis
}

\author{
Luciana Poddighe ${ }^{1}$, Giuseppe Mameli ${ }^{1}$, Alessandra Mei ${ }^{1}$, Elena Uleri ${ }^{1}$, Caterina Serra ${ }^{1}$, Roberto Manetti ${ }^{2}$,
} Antonina Dolei ${ }^{i^{*}}$

From Frontiers of Retrovirology 2011

Amsterdam, The Netherlands. 3-5 October 2011

\section{Background}

Multiple sclerosis (MS) is a chronic inflammatory disease of the central nervous system, with demyelination and gliosis. Proposed pathogenic co-factors triggering MS pathogenesis are the Epstein Barr virus (EBV), and two elements of the $W$ family of human endogenous retroviruses (HERV-W): MSRV, that forms free virions, and syncytin-1, the ERVWE1env protein; both retroelements have neuropathogenic properties. In the past we studied MSRV in MS patients in various temporal and clinical stages; in all cases, striking parallelisms between MS behaviour and MSRV/HERV-W presence/ load were found. By simultaneous detection of MSRV and HHV-6, we found a direct correlation between MS and MSRV presence/load, but not for HHV-6. MS brains over-express MSRVenv and syncytin-1 transcripts, with respect to controls, while EBV presence was not detected.

\section{Materials and methods}

Since late EBV seroconversion is a strong risk factor for MS development, we performed in vitro experiments on PBMC from MS patients and MSRV ${ }^{+}$volunteers, as well as on U87-MG astroglioma cells, that were studied as such or were exposed to EBV or to recombinant EBV glycoprotein350 (EBVgp350), or to proinflamma-

'Department of Biomedical Sciences and Center of Excellence for Biotechnology Development and Biodiversity Research

Full list of author information is available at the end of the article tory cytokines. The levels of MSRVenv and syncytin-1 mRNAs were evaluated by discriminatory real time RTPCR assays. Flow cytometry was used to evaluate the HERV-Wenv protein on the plasmamembrane, as well the PBMC subsets.

\section{Results}

Basal expression of MSRVenv and syncytin-1 occurs in astrocytes and in NK, B and monocyte cells, but not in $\mathrm{T}$ cells. This uneven expression is amplified in naive MS patients. Astrocyte infection by EBV and exposure to EBVgp350 stimulate the expression of HERV-W/MSRV/ syncytin-1, with requirement of the NF- $\kappa$ B pathway. In EBVgp350-treated PBMC, MSRVenv and syncytin-1 are activated in B cells and monocytes, but not in T cells, nor in the highly expressing NK cells. The latter cells, but not the $\mathrm{T}$ cells, are activated by proinflammatory cytokines.

\section{Conclusions}

The study demonstrates that there are interactions among the above proposed MS-cofactors. In vivo, a pathogenic outcome would depend on activation in abnormal situations/tissues, as it may occur in delayed EBV infection, or in the presence of particular host genetic backgrounds, or both.

\footnotetext{
Author details

${ }^{1}$ Department of Biomedical Sciences and Center of Excellence for Biotechnology Development and Biodiversity Research. ${ }^{2}$ Department of Clinical, Experimental and Oncological Medicine, University of Sassari, 07100 Sassari, Italy.
} 
doi:10.1186/1742-4690-8-S2-P19

Cite this article as: Poddighe et al:. Expression and activation of human endogenous retroviruses of the W family in blood cells and astrocytes: implications for the pathogenesis of multiple sclerosis. Retrovirology 2011 8(Suppl 2):P19.

Submit your next manuscript to BioMed Central and take full advantage of:

- Convenient online submission

- Thorough peer review

- No space constraints or color figure charges

- Immediate publication on acceptance

- Inclusion in PubMed, CAS, Scopus and Google Scholar

- Research which is freely available for redistribution

Submit your manuscript at www.biomedcentral.com/submit
() Biomed Central 